\title{
Cyclic Behavior of Steel Beam-to-Column Moment Connections Using Different Sizes of Flange Plates and Reinforced by a Single Rib Plate
}

\author{
Abbas Haghollahi ${ }^{a}$, Hassan Ahmadi ${ }^{{ }^{*}}$ \\ a Faculty of Civil Engineering, Shahid Rajaee Teacher Training University,Tehran, Iran.
}

Received 31 December 2017; Accepted 28 January 2018

\begin{abstract}
This paper presents a numerical study on the behavior of connection between steel I-beam and H-column when are affected by cyclic loading. The connection used the flange plates to connect the beam flanges to the column flange. They were welded to the top and bottom flange plates and created a welded flange plate (WFP) connection. Specimens were six models of WFP connections with different beam geometry and flange plate sizes which were modeled and their cyclic behavior were investigated using finite element analysis in ABAQUS program. Three of them were reinforced by a vertical triangular top and bottom rib plates, and others remained unreinforced. The results showed that reinforcement with a vertical triangular rib plate attached to the top and bottom flange plates can improve cyclic behavior of WFP connections. By using a rib plate, the equivalent plastic strain was increased and showed better plastic hinge formation compared to those with no vertical rib plate. Those models with IPB beam sections had the best cyclic behavior compared to those with IPE beam sections and satisfied the acceptance criteria of AISC seismic provisions for intermediate and special moment frames. We concluded that those WFP connections which did not satisfy the criteria of AISC seismic provisions for special moment frames, can be upgraded by a vertical triangular rib plate in order to be used in special moment frames.
\end{abstract}

Keywords: Welded Flange Plate Connection; Steel Moment Connection; Reinforcement; Rib Plate; Finite Element Analysis.

\section{Introduction}

One of the most common moment connections that are used by designers especially after Northridge earthquake (1994) which caused brittle fracture in or around the groove weld between the beam and the column flange in moment frame connections is welded flange plate (WFP) connections. In this connection, the applied moment and the shear force are transferred to the column flange through the top and the bottom flange plates and a shear plate (or shear tab), respectively where top and bottom flange plates have the same width and length [1]. Using WFP connections, it will force the formation of the plastic hinge away from the face of the column while preventing the brittle failure of the moment connection [2]. WFP connection is classified as a prequalified welded fully restrained connection in FEMA $350[3]$.

A number of numerical and experimental studies have been conducted on the behavior of WFP connections. Among recent studies, Deylami and Toloukian [4] conducted nonlinear finite element analyses to investigate the effect of geometry of vertical rib plate on cyclic behavior of these connections, and concluded that the reinforcement provided by the vertical ribs plates can reduce the stress concentration on the complete joint penetration weld which in turn decreases the risk of brittle fracture of this weld. Maranian et al. [5] reviewed the research and testing carried out on

* Corresponding author: hassanahmadi.srttu@gmail.com

\section{doi http://dx.doi.org/10.28991/cej-030975}

> This is an open access article under the CC-BY license (https://creativecommons.org/licenses/by/4.0/).

(C) Authors retain all copyrights. 
these connections for the SAC Joint Venture and suggested that the WFP connection should not be classified as prequalified method in FEMA 350 for special moment frames. Deylami et al [6] presented analytical and experimental study on the cyclic behavior of these connections between a steel beam and a welded box column by evaluating the effect of beam depth on the seismic response of flange plate connection. Their test results indicated that a deeper beam can lead to a greater potential for fracture in the groove weld joining the beam web to the beam flange at the plastic hinge region. By conducting a cyclic test, Lee et al. [7] in an experimental study showed that WFP connections had more than $3 \%$ story drift capacity, which satisfy the required performance for ordinary moment frame systems. Sanee Nia et al. [8] studied cyclic performance of flange-plate connection to box column with finger shaped plate. The proposed configuration include a longitudinal fillet weld used in flange plates plus a transverse fillet and slot weld in the top and bottom of flange plates, respectively; so that it can provide the required strength for welds. The study results indicated that the flange plate connection with the suggested configuration could be used in the special moment frames. Hedayat et al. [9] investigated their strength and ductility based on the geometrical properties of the connected beam using the finite element method. In this regard, they designed and analyzed more than 85 WFP connections with different beam overall depths, beam flanges and web slenderness ratios. Their results showed that the behavior of a WFP connection is highly affected by the slenderness of the beam elements. Moreover, they found out that for a WFP connection with a deep beam employed in a special moment frame, by limiting the width-to-thickness ratios of the beam flanges and web plates, we can not achieve the appropriate strength and ductility for these connections.

In a parametric study by Hedayat et al. [10], effective parameters on the strength and ductility of the WFP connections including beam material property, thickness of flange plate, length of flange plate, the transverse welding of the top flange plates, the top flange plate's end form, the equality or inequality of the length of top and bottom flange plate, shape of the rib plates and the common methods of the beam-to-column shear force transfer were investigated. Hernandez [2] in a finite element analysis, showed that increasing the thickness of the cover plates, increase the connection capacity and strength. Kosarieh and Danesh [11] studied effects of panel zone yielding on the seismic performance of WFP connections under cyclic loading for external joints in steel moment resisting frames. Their results reported a high connection rotation capacity for all specimens, and those with different panel zone strengths provided different amount of energy dissipation. A tearing along the k-line area of the beam in the plastic hinge location occurred after a severe beam buckling, in addition to the tearing of the beam at the tip of the bottom flange plates; both were as a predominant failure mode observed in the specimens with a stronger panel zone. The specimens with weak panel zone were able to have a significant plastic rotation without damaging the beam-to-column connection groove welds. The effects of different levels of column axial load on seismic performance of WFP connections with different panel zone strength were investigated by Kosarieh et al. [12] using finite element analysis. Their results revealed that cyclic behaviour including hysteresis loops and energy dissipation were not affected significantly by increasing column axial load regardless of the panel zone strength. Gholami et al. [13] studied the behavior of flange plate connection between a steel beam and a welded box column finite element models, and proposed that it is better to reduce the required flange plate length by using higher strength weld, and increase the weld thickness as far as possible. Farooghi Mehr and Ghobadi [14] proposed defected complete joint penetration groove weld at the only top flange of the connection and highly ductile box columns with ribs for retrofitting WFP connections.

Welded flange plate connections are also popular in Iran while its configuration and fabricating processes are different from those of FEMA350 which can cause different behavior. According to the tenth code of Iranian national building regulations [15], WFP connections are allowed to be used only in intermediate moment frames, but in the studies conducted presented in [6-8,13],WFP connections achieved the AISC seismic provision requirements for special moment frames, as well. Considering these conflicts, in this study, we attempted to examine the usability of WFP connections in special and intermediate moment frames. According 2005 AISC provisions [16], at special moment frames (SMFs), the flexural strength at the column face at 0.04 rad story drift should not be less than $80 \%$ of the beam plastic moment capacity $(0.8 \mathrm{Mp})$, and the connection should be stable until the total rotational angle reached $0.04 \mathrm{rad}$. For intermediate moment frames (IMFs), inelastic rotation capacity should be up to $0.02 \mathrm{rad}$, and the flexural capacity of the specimen at the column face should not be less than $80 \%$ of the beam plastic moment at 0.02 rad story drift. We simulated the behavior of these connections with different beam geometry and flange-plate dimensions using finite element $(\mathrm{FE})$ analysis and examined the effect of reinforcement with a vertical single rib plate on their cyclic behavior

\section{Nonlinear Finite-Element Analysis}

The analytical study involves developing FE model of connections in ABAQUS software for evaluating the cyclic behavior of unreinforced and reinforced WFP connections. 


\subsection{Frame and Connection}

A 10-storey structure with steel moment-resisting frame was designed according to common design procedure in Iran with WFP connections. The structure has a 6-m span and a floor height of $3 \mathrm{~m}$ located in Azna County, Lorestan Province, Iran with a high relative risk of earthquake. Its storey dead and live loads are 600 and $200 \mathrm{Kgf} / \mathrm{m}^{2}$, respectively. Lateral restraint is considered for beams according to AISC provisions, and Iranian national building regulations. Design of connection elements is based on Load and Resistance Factor Design (LRFD) method and Iranian national building regulations. We used exterior T-shaped joint model as a subassemblage for connection study. It is assumed that the column is pin-supported at mid-story, and the beam is pin-supported at mid-span. Figure 1 shows the designed frame and the subassemblage model. Details of designed H-shaped column and I-shaped beam are presented in Figure 2.

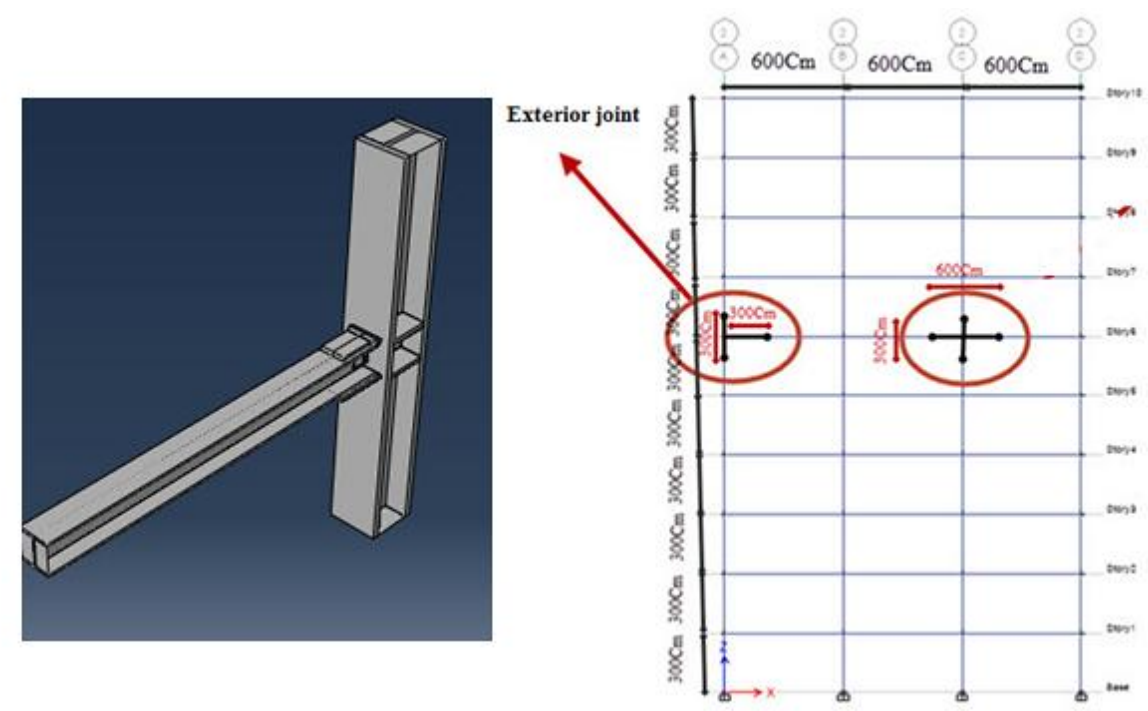

Figure 1. Plan of designed frame (right) and typical subassemblage model (left)
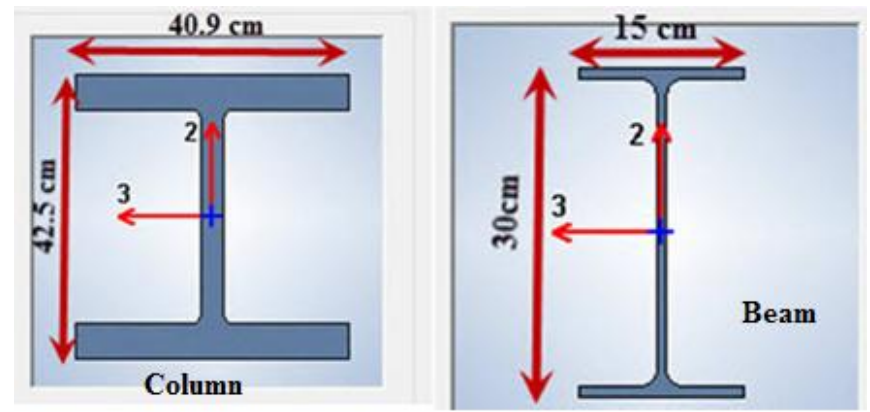

Figure 2. Details of designed H-shaped column and I-shaped beam

\subsection{Specimens}

Six models of WFP connection were designed in this study where top and bottom flange plates were groove welded to the column flange. Details of specimens are presented in Table 1. In A200-T, B300-T, and C240-T specimens, a triangular rib plate with the dimensions of $100 \times 100 \times 80 \mathrm{~mm}$ was vertically fillet welded to the top and bottom flange plates for reinforcement, while A200, B300, and C240 models remained unreinforced. All models consisted of Hshaped steel columns with the dimensions of $\mathrm{H}-400 \times 409 \times 526 \times 32.8 \mathrm{~mm}$ and web plates with the measurements of $15 \times 12 \times 1 \mathrm{~cm}$, but with different beam geometry and flange-plate dimensions (width, length, and thickness) according to [15]. C240 and C240-T specimens consist of IPB beam sections, while others have IPE beam sections. Figure 3 presents the details of designed flange plates and web plates.

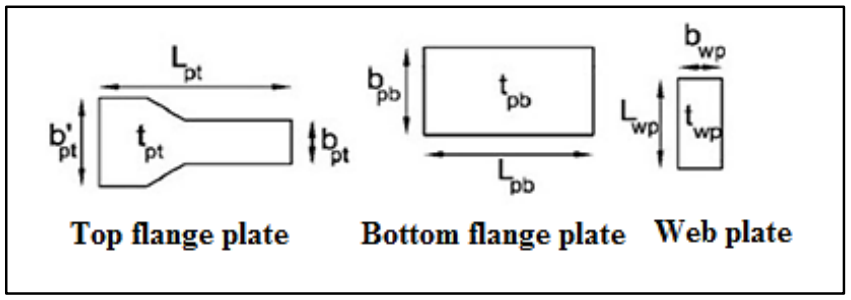

Figure 3. Geometry of flange plates and web plates 
Table 1. Details of test specimens

\begin{tabular}{|c|c|c|c|c|c|c|c|c|c|c|c|c|c|}
\hline \multirow{2}{*}{ Model } & \multirow{2}{*}{$\begin{array}{l}\text { Beam } \\
(\mathbf{m m})\end{array}$} & \multirow{2}{*}{ Column (mm) } & \multicolumn{3}{|c|}{$\begin{array}{c}\text { Bottom flange- } \\
\text { plate }(\mathrm{cm})\end{array}$} & \multicolumn{4}{|c|}{ Top flange-plate $(\mathrm{cm})$} & \multirow{2}{*}{$\begin{array}{l}\text { Triangular rib } \\
\text { plate }(\mathbf{m m})\end{array}$} & \multicolumn{3}{|c|}{ Web plate (cm) } \\
\hline & & & $l_{p b}$ & $b_{p b}$ & $t_{p b}$ & $l_{p t}$ & $b_{p t}$ & $\boldsymbol{b}_{p t}^{\prime}$ & $t_{p t}$ & & $l_{w p}$ & $b_{w p}$ & $t_{w p}$ \\
\hline A200 & IPE200 & H- $400 \times 409 \times 526 \times 32.8$ & 25 & 15 & 1.5 & 20 & 6 & 10 & 1.5 & - & 15 & 12 & 1 \\
\hline A200-T & IPE200 & H- $400 \times 409 \times 526 \times 32.8$ & 25 & 15 & 1.5 & 20 & 5 & 7 & 1.5 & $100 \times 100 \times 80$ & 15 & 12 & 1 \\
\hline B300 & IPE300 & H- $400 \times 409 \times 526 \times 32.8$ & 30 & 20 & 2 & 30 & 10 & 15 & 2.5 & & 20 & 12 & 1 \\
\hline B300-T & IPE300 & H- $400 \times 409 \times 526 \times 32.8$ & 30 & 20 & 2 & 30 & 10 & 15 & 2.5 & $100 \times 100 \times 80$ & 20 & 12 & 1 \\
\hline $\mathrm{C} 240$ & IPB240 & H- $400 \times 409 \times 526 \times 32.8$ & 40 & 30 & 2.5 & 35 & 20 & 25 & 3.5 & - & 15 & 12 & 1 \\
\hline $\mathrm{C} 240-\mathrm{T}$ & IPB240 & H- $400 \times 409 \times 526 \times 32.8$ & 40 & 30 & 2.5 & 35 & 20 & 25 & 3.5 & $100 \times 100 \times 80$ & 15 & 12 & 1 \\
\hline
\end{tabular}

\subsection{Meshing}

Section Eight-node brick element (C3D8I) in ABAQUS was used for meshing WFP connection and its elements, which is shown in Figure 4. The size of mesh near the connected area is $10 \mathrm{~mm}$, and in farther areas, it is $50 \mathrm{~mm}$. According to typical procedure in ABAQUS, the boundary conditions hinged at each end of column through modeling a rigid plate using shell element with six degrees of freedom per node, and connecting it to both ends of column based on Tie constraint.
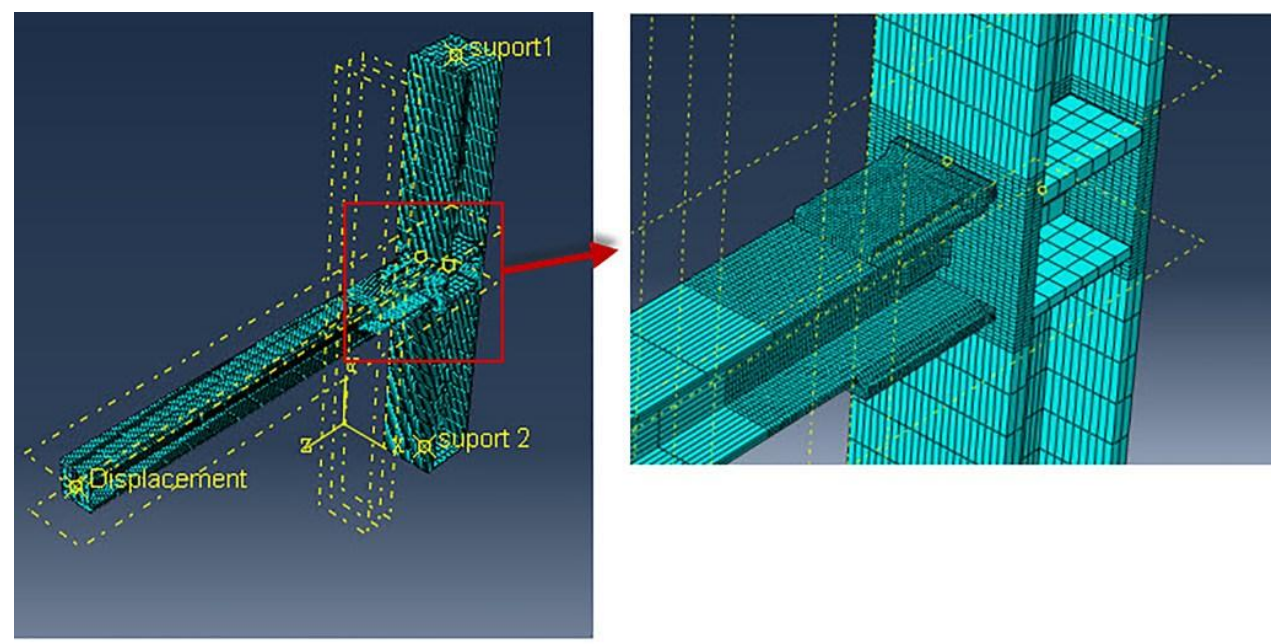

Figure 4. Finite element model of a typical WFP connection

\subsection{Material Modeling}

Bilinear stress-strain relationship was considered to define material properties (Figure 5). All materials had Poisson's ratio of 0.3 . Table 2 presents the material properties used for FE modeling. For modeling weld material, we used the test data presented by Kaufmann [17]. It should be mentioned that von-Mises yield criterion was used to model the plastic deformation of materials, and kinematic hardening rule was employed for ratcheting prediction on steels.

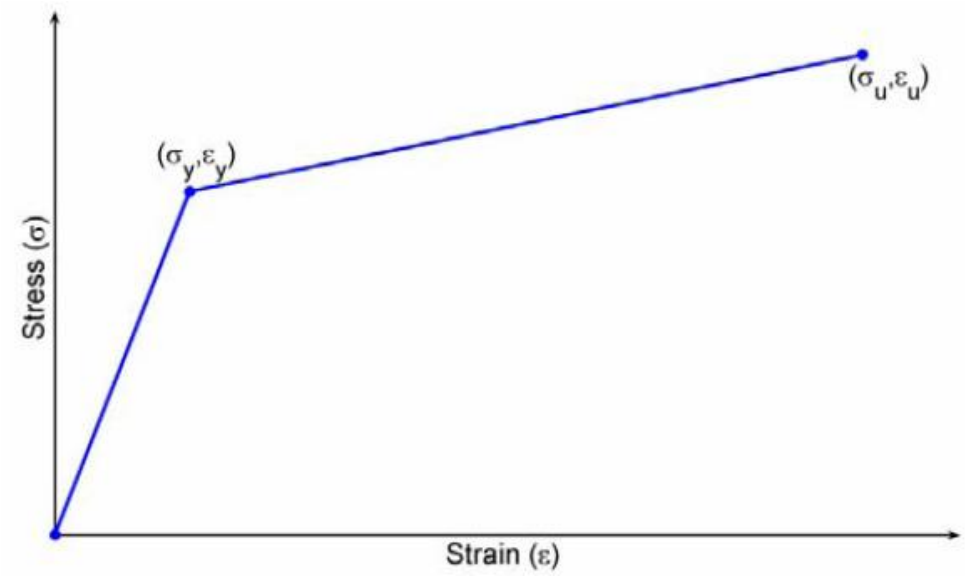

Figure 5. Assumed bilinear stress-strain relationship for ABAQUS models [13] 
Table 2. Properties of material used for the models

\begin{tabular}{ccccccc}
\hline & & & \multicolumn{2}{c}{ Yield point } & \multicolumn{2}{c}{ Ultimate point } \\
\cline { 4 - 7 } Material & Young modulus & Strain hardening & Stress (MPa) & Strain (\%) & Stress (MPa) & $\begin{array}{c}\text { Strain (\%) } \\
\text { (Mpa) }\end{array}$ \\
\cline { 4 - 7 } & Modulus (Mpa) & $\boldsymbol{\sigma}_{\boldsymbol{y}}$ & $\boldsymbol{\varepsilon}_{\boldsymbol{y}}$ & $\boldsymbol{\sigma}_{\boldsymbol{u}}$ & $\boldsymbol{\varepsilon}_{\boldsymbol{u}}$ \\
\hline Steel & 200000 & 6000 & 300 & 0.15 & 420 & 18 \\
\hline \multirow{2}{*}{ Weld } & 200000 & 6000 & 520 & 0.26 & 560 & 12 \\
\hline
\end{tabular}

\subsection{Loading}

For testing cyclic behavior of specimens, a displacement-control loading was applied to the tip of the beam based on ATC-24 protocol [18] which is shown in Figure 6. It consists of six cyclic loading starting with initial cycles of low energy input, within the elastic range of behavior and progressing to increasing deformation until failure occurs. The beam tip displacement is corresponding to inter-story drift angle.

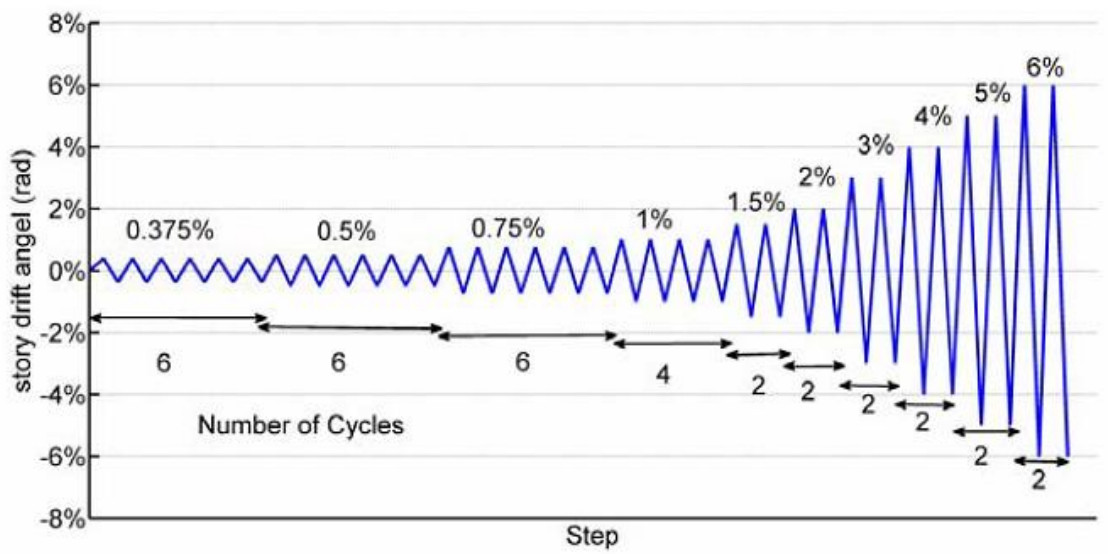

Figure 6. Assumed load history for cyclically loaded connection [13]

\section{6. . Test Verification}

Numerical results were benchmarked with experimental results of Gholami et al. [13] to validate the accuracy and applicability of simulated finite element models of WFP connections. Figure 7 depicts the model tested by Gholami et al., where H-shaped steel beam with the dimensions of $\mathrm{H}-380 \times 200 \times 8 \times 12(\mathrm{~mm})$ was connected to a box column with the measurements of B-400 $\times 400 \times 20 \times 20(\mathrm{~mm})$ with a WFP moment connection type. The width-thickness ratios of the beam flange and the web are 8.33 and 44.5, respectively. Connection details can be found in Reference [13]. We compared the moment at column face versus story drift results of Gholami et al. and those of numerical results (Figure 8) which indicates a close agreement between them (error rate $=7 \%$ ). In this regard, it can be said that the numerical results in this study were validated.

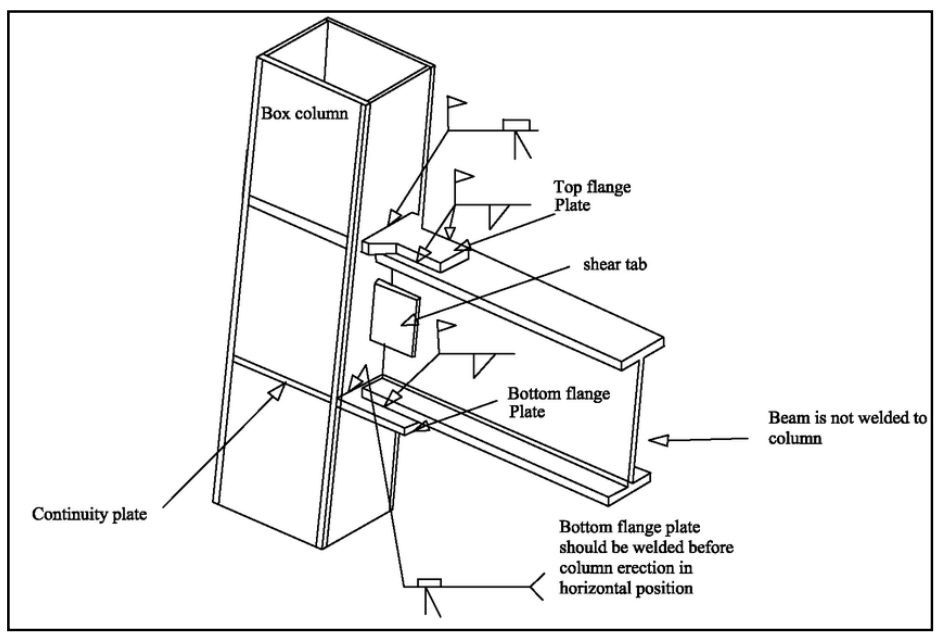

Figure 7. WFP connection model used in Reference [13] 


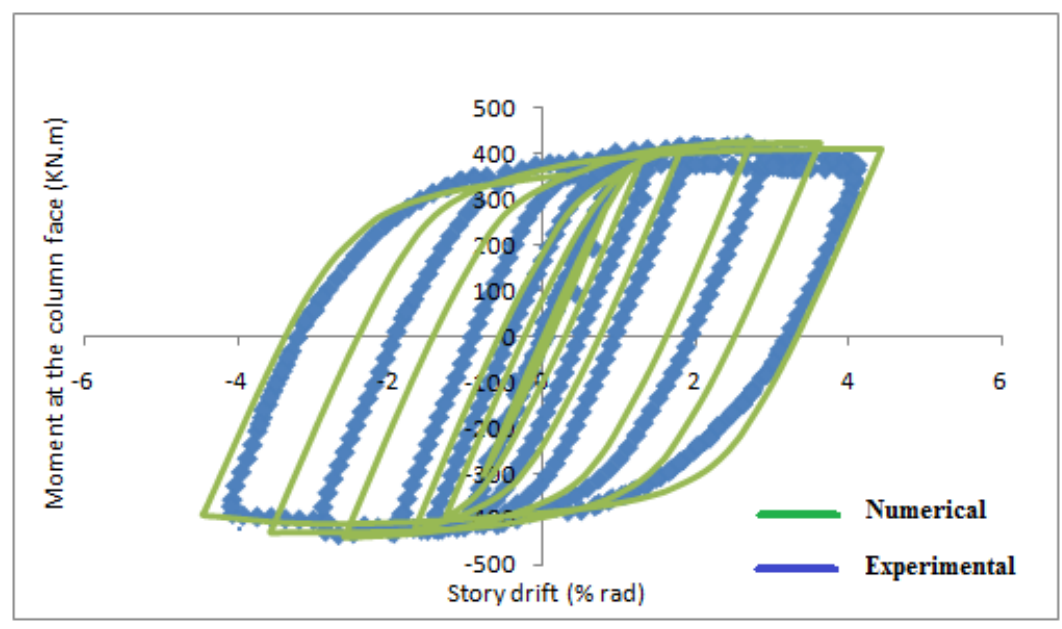

Figure 8. Moment-rotation hysteric curves of FE models vs. experimental models

\section{Numerical Results}

\subsection{Stress and Equivalent Plastic Strain Distributions}

The Von Mises stress distributions for 0.04 rad story drift angle shown in Figure 9. It was shown that at the plastic hinge region, and in the area where top and bottom flange plates had welded to the column flange, the stress of elements was increased. The equivalent plastic strain distributions (PEEQ index) for 0.06 rad story drift angle are shown in Figure 10. Equivalent plastic strain was used to measure inelastic local strain demands, which is defined as the ratio of the equivalent plastic strain to the yield strain. Results showed that by moving far from the beam-column interface, equivalent plastic strain increase such that its largest amount occurred far from the connected zone and at the end of top and bottom flange plates and groove welds which indicates the formation of plastic hinges at the end of flange plates. By using vertical rib plate for reinforcement, maximum PEEQ index was increased and showed better plastic hinge formation compared to those with no vertical rib plate. In addition, it can be observed that the increase in the height of the beam increases the PEEQ index in the plastic hinge location; therefore, WFP connections with a larger beam height have the potential to brittle fracture in the joint area, and a soft failure (rupture) in the plastic hinge area.

\subsection{Hysteretic Curves}

To investigate the strength of the connections, moment-rotation hysteretic curves of all specimens and their panel zones are extracted using FE analysis. The bending moment $(\mathrm{M})$ at the column face versus story drift angle $(\theta)$ can be defined as:

$$
\begin{aligned}
& M=P \times L_{b} \\
& \theta=\frac{\Delta}{\left(L_{b}+\frac{d_{c}}{2}\right)}
\end{aligned}
$$

Where, $P$ shows actuator force; $l_{b}$ is beam length; $d_{c}$ shows column depth, and $\Delta$ represents displacement. In addition, in order to examine the influence of panel zone (PZ) on the cyclic behavior of specimens, moment-PZ rotation hysteretic curves were plotted which can be written as:

$$
\gamma_{P Z}=\frac{\sqrt{a^{2}+b^{2}}}{2 a b}\left(\delta_{1}-\delta_{2}\right)
$$

Where $a$ and $b$ show initial length and width of panel zone, $\delta_{1}$ and $\delta_{2}$ are changes in length of panel zone diagonals.

Moment-plastic rotation hysteretic curves of all models are presented in Figure 11. According to the results, as the height of the beam increases in equal rotations, strength reduction occur earlier due to the local buckling of the beam web and flange after cyclic loading.

For unreinforced specimen A200, hysteretic curves showed a local buckling occurrence in beam flange at $0.036 \mathrm{rad}$ drift angle, which caused the web local buckling. This led to strength reduction in this model. The reduction rate in the last loading cycle $(0.06 \mathrm{rad})$ was $25.47 \%$. This model was sustainable until $0.036 \mathrm{rad}$. Although the moment at 0.04 rad rotation is more than $0.8 \mathrm{MP}$, but due to the web buckling occurred at 0.039 rad rotation, this model did not satisfy the criteria of AISC seismic provisions for SMF systems; although it satisfied the criteria for IMF systems. 
In specimen A200-T that was reinforced with a vertical triangular rib plate, the beam flange was locally buckled at $0.041 \mathrm{rad}$ and caused local buckling in the web, and reduced the connection strength. The rate of strength reduction at $0.06 \mathrm{rad}$ was $25.86 \%$. Since this model was stable until 0.04 rad rotation, (both flange and web local buckling occurred at $0.041 \mathrm{rad}$ ); therefore, it satisfied the criteria for both SMF and IMF systems.

For specimen B300 with larger dimensions of top and bottom flange plates compared to A200 and A200-T models, the local buckling in beam flange occurred at $0.035 \mathrm{rad}$, which caused buckling in the web and resulted in strength reduction with a rate of $24.32 \%$ at 0.06 rad story drift. Although the moment at the column face at 0.04 rad was higher than $0.8 \mathrm{Mp}$, but due to the occurrence of web local buckling at $0.035 \mathrm{rad}$, it did not satisfy the criteria of AISC seismic provisions for SMF systems, but was in agreement with the criteria for IMFs.

In specimen B300-T, the beam local buckling occurred at $0.038 \mathrm{rad}$ and then caused web buckling which led to strength reduction with a rate of $18.46 \%$ at 0.06 rad story drift. This model, similar to A200 and B300 models, did not satisfy the criteria of AISC seismic provisions for SMFs due to the web buckling at $0.038 \mathrm{rad}$, but could satisfy the criteria for IMFs.

For specimen C240 with bigger top and bottom flange plates compared to A200, A200-T, B300, and B300-T models, results showed neither flange local buckling nor web local buckling which indicates high energy absorption and favorable behavior of this connection. This is because of the increase in the beam moment inertia. Consequently, this connection satisfies the criteria of AISC seismic provisions for both SMF and IMF systems.

In specimen C240-T with the same top and bottom flange-plate dimensions as those of C240 model, flange local buckling occurred $0.05 \mathrm{rad}$, which reduced the strength of connection such that the reduction rate in the last loading cycle was reported as $5.15 \%$. Since the moment at the column, face was higher than $0.8 \mathrm{Mp}$ at 0.04 rad rotation, and the connection was stable up to $0.05 \mathrm{rad}$ story drift; therefore, this model satisfies the criteria of AISC seismic provisions for both SMF and IMF systems.

The moment-PZ rotation curves for all specimens are shown in Figure 12. The maximum positive rotation angle $\left(\theta_{\max }^{+}\right)$and maximum negative rotation angle $\left(\theta_{\max }^{-}\right)$for specimens A200, B300, and C240 with no attached vertical rib plate were +0.0001544 and $-0.0001524 \mathrm{rad} ;+0.0002845$ and $-0.0002789 \mathrm{rad}$; and +0.0004424 and $-0.0004226 \mathrm{rad}$, respectively. For specimens with attached vertical rib plate, A200-T, B300-T, and C240-T, $\left.\left(\theta_{\max }^{+}\right)\right)$and $\left(\theta_{\max }^{-}\right)$were reported as +0.0001396 and $-0.0001374 \mathrm{rad} ;+0.0002677$ and $-0.0002644 \mathrm{rad}$; and +0.0004577 and $-0.0004385 \mathrm{rad}$, respectively. It can be found out that due to the use of vertical rib plate, the strength of the connections have increased which reduced rotation at both positive and negative loading cycles. Moreover, it can be observed that in specimens A200, A200-T, C240, and C240-T, plastic deformation is linear at positive and negative loading cycles, while in B300 and B300-T models, the plastic deformation is linear at the first loading cycle and then at the next cycles, they has been deformed nonlinearly. Results also showed that by increasing the beam height and moment of inertia, the stiffness of the connection nodes increased. By increasing the moment of inertia in the beam, cyclic behavior of WFP connections became better.

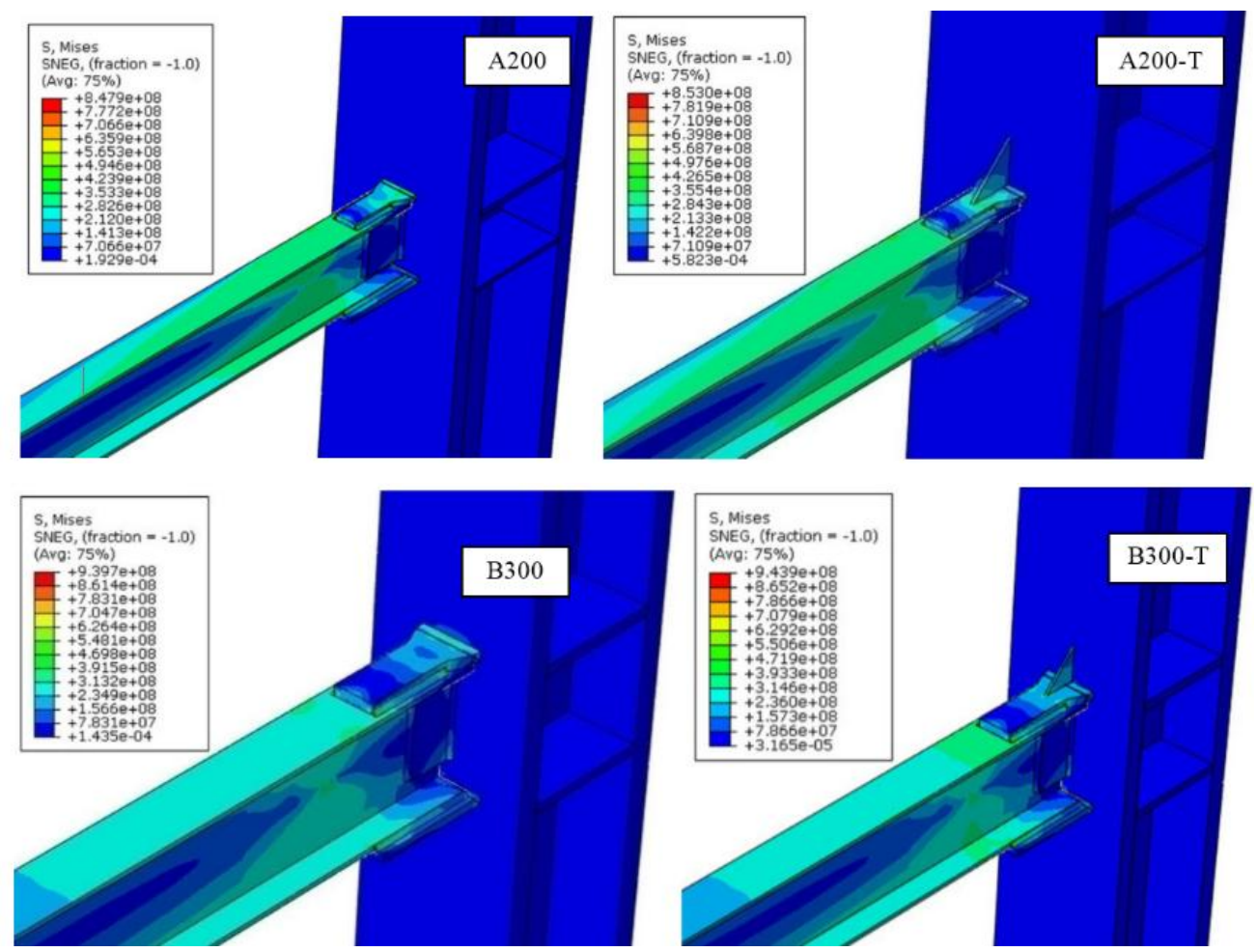



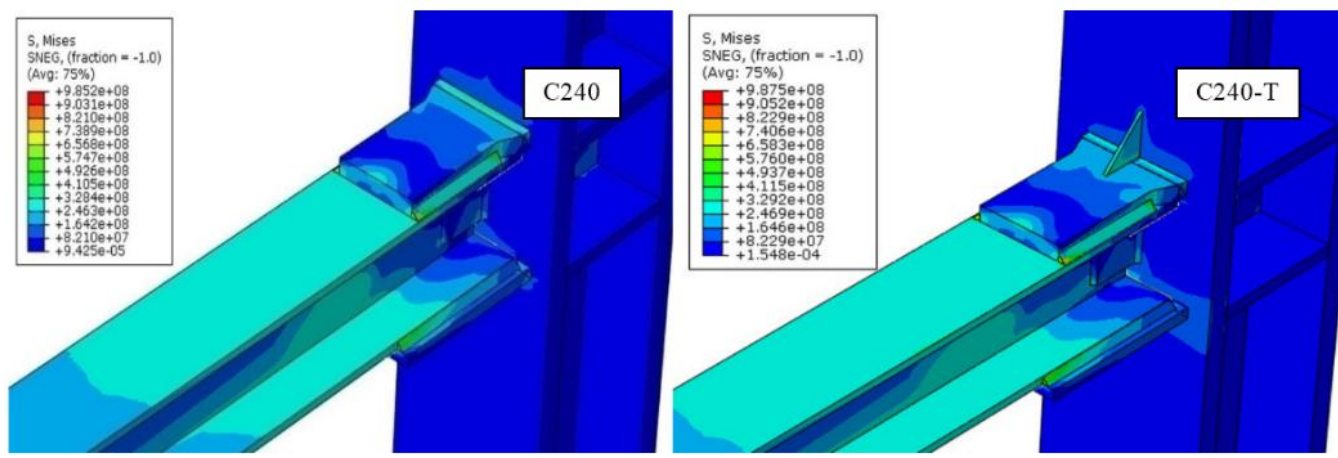

Figure 9. Von Mises stress distributions of specimens for 0.04 rad story drift angle
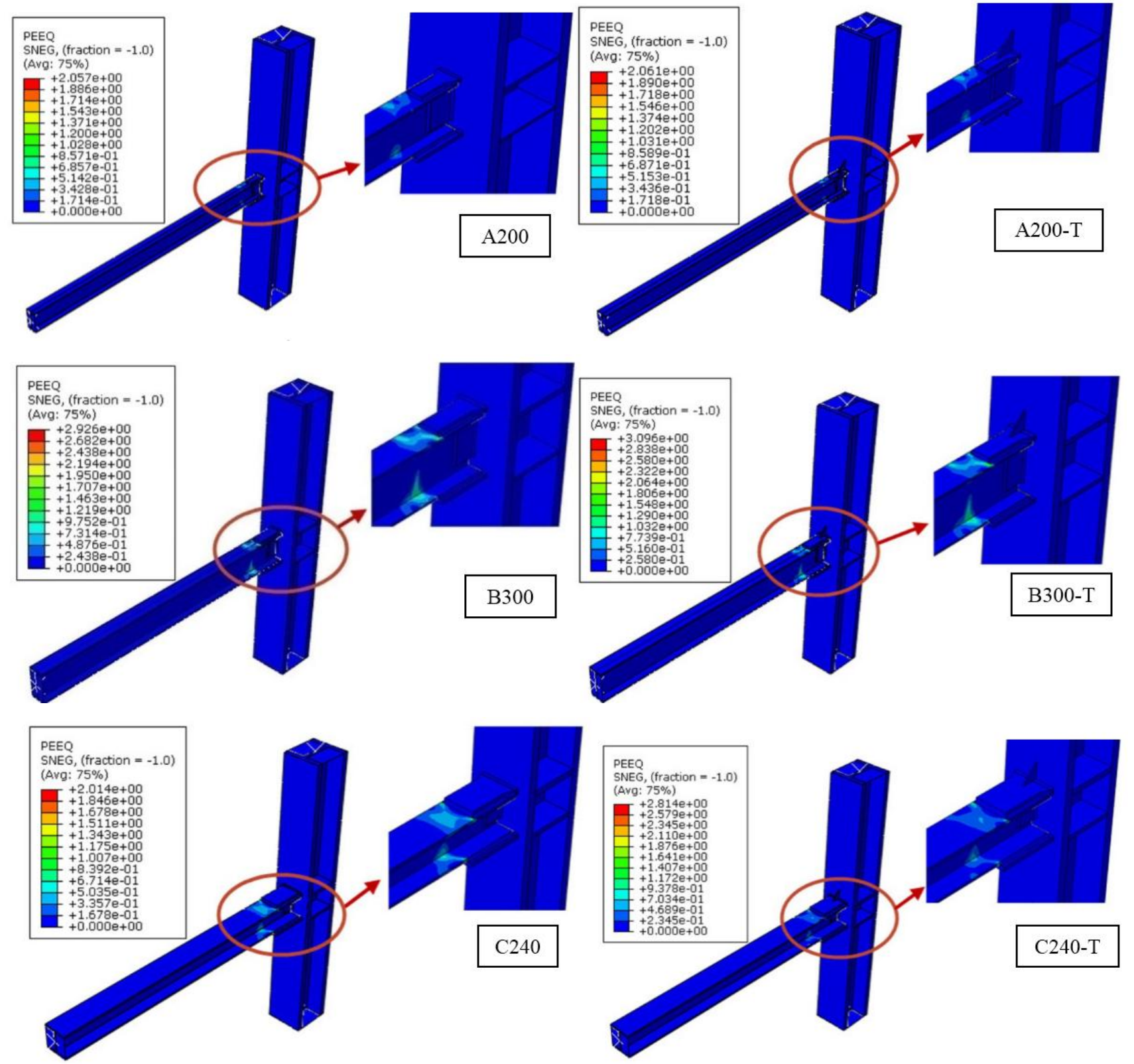

Figure 10. The PEEQ index of specimens for 0.06 rad story drift angle 


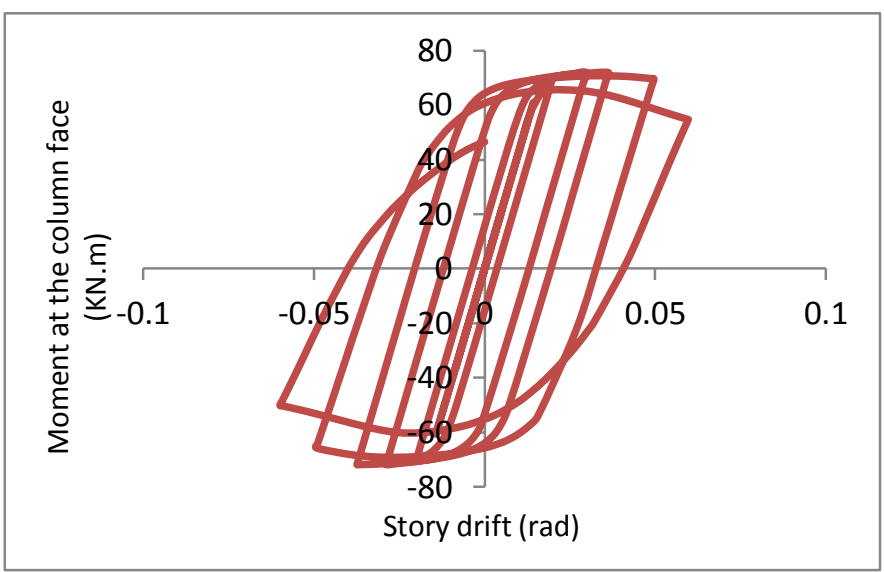

(a) Specimen A200

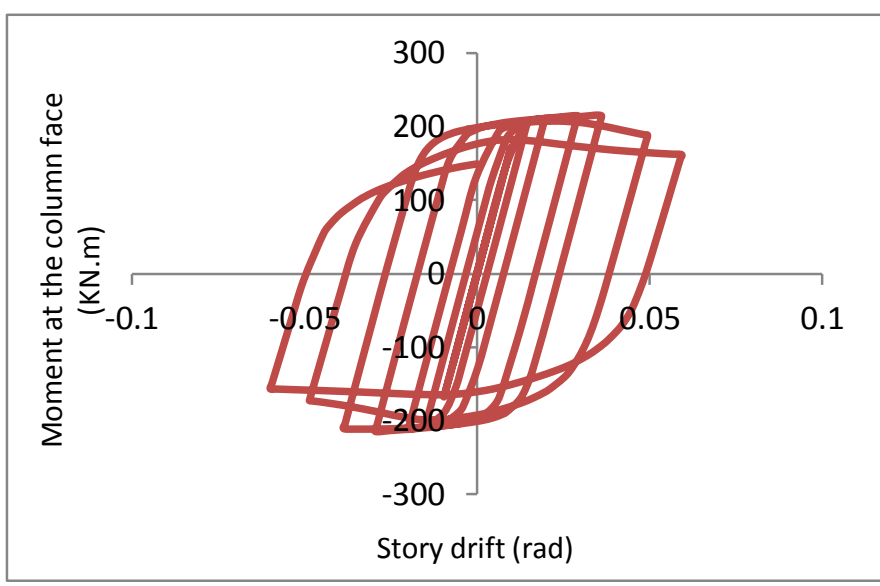

(c) Specimen B300

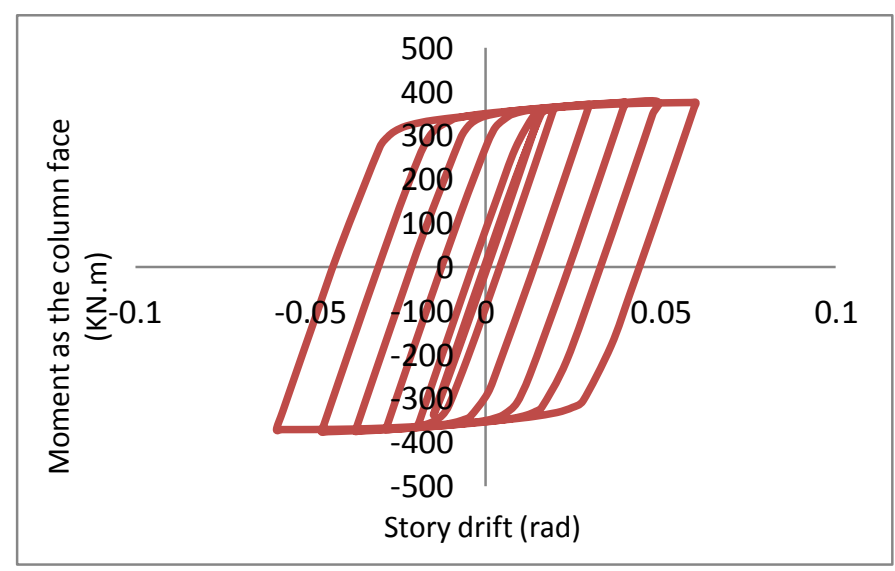

(e) Specimen C240

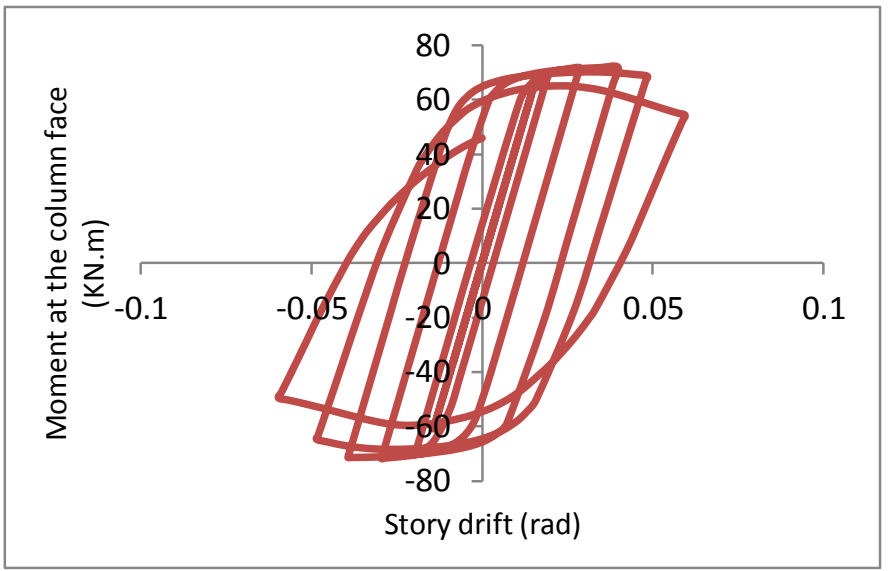

(b) Specimen A200-T

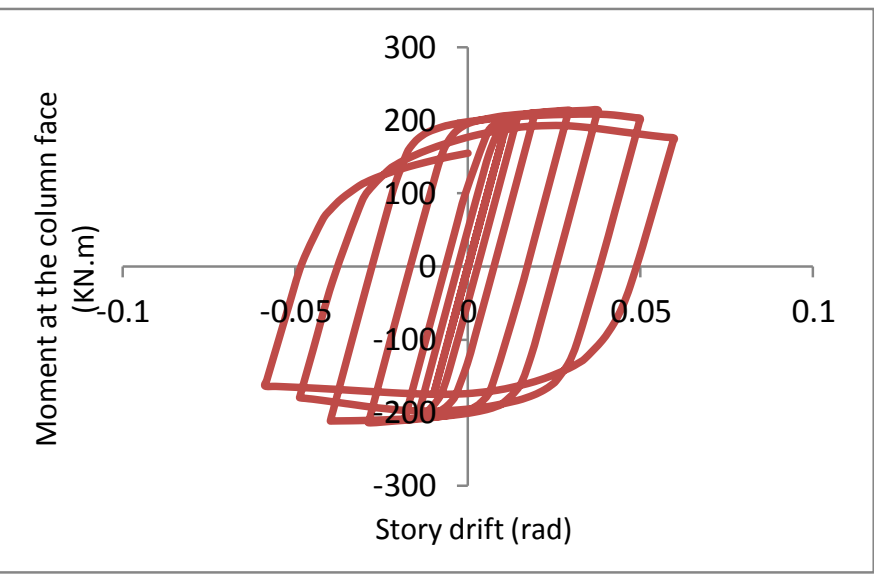

(d) Specimen B300-T

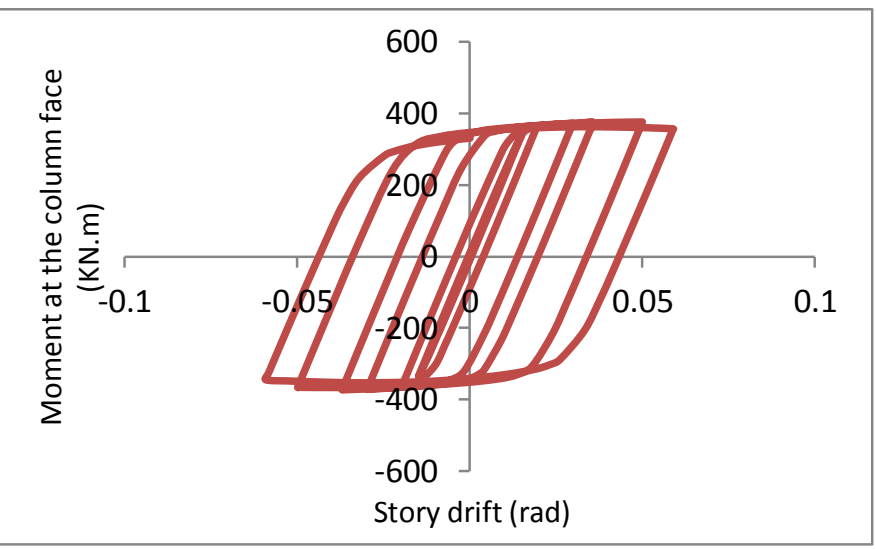

(f) Specimen C240-T

Figure 11. Moment at the column face vs. story drift relationships of specimens 


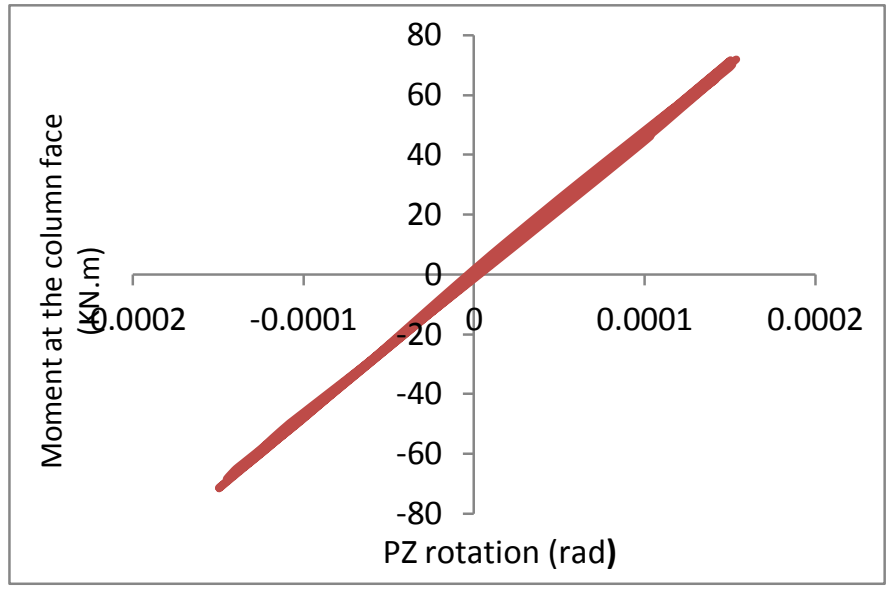

(a) Specimen A200

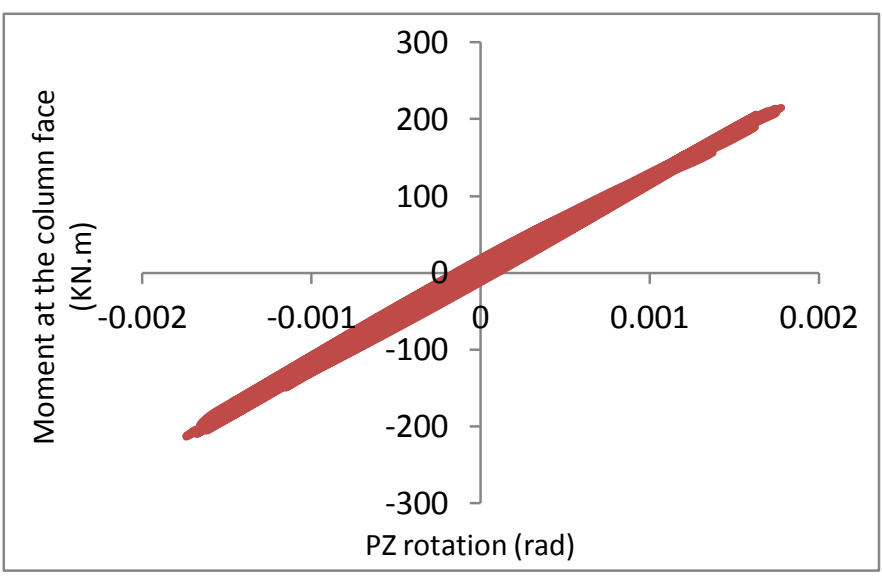

c) Specimen B300

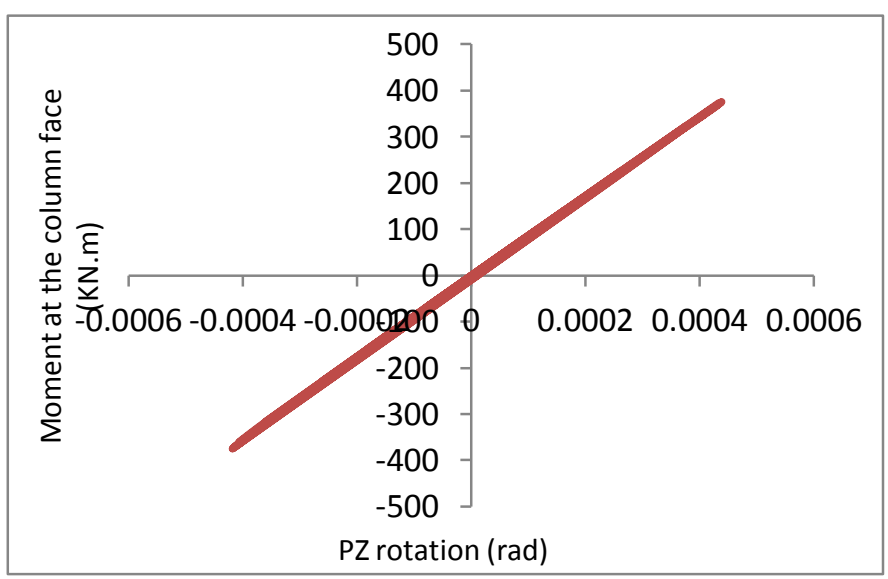

(e) Specimen C240

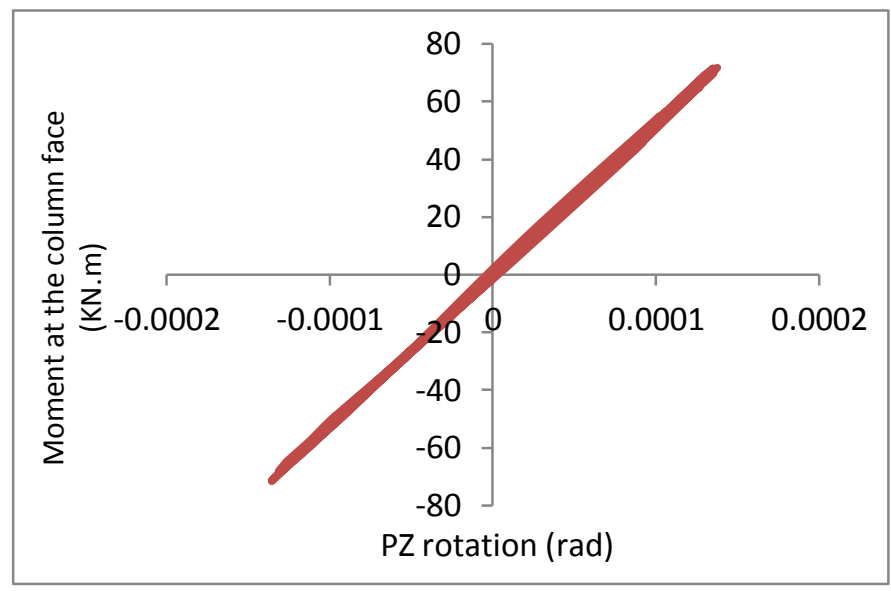

(b) Specimen A200-T

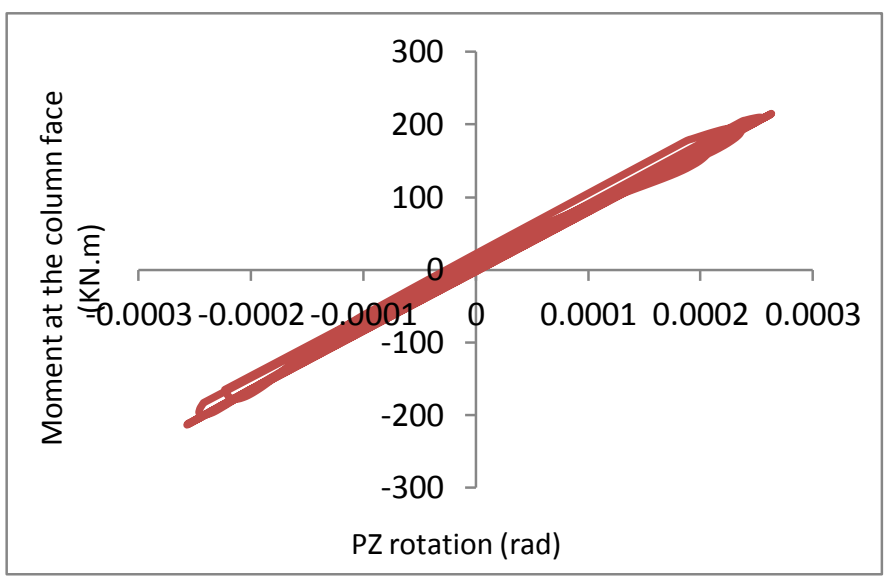

(d) Specimen B300-T

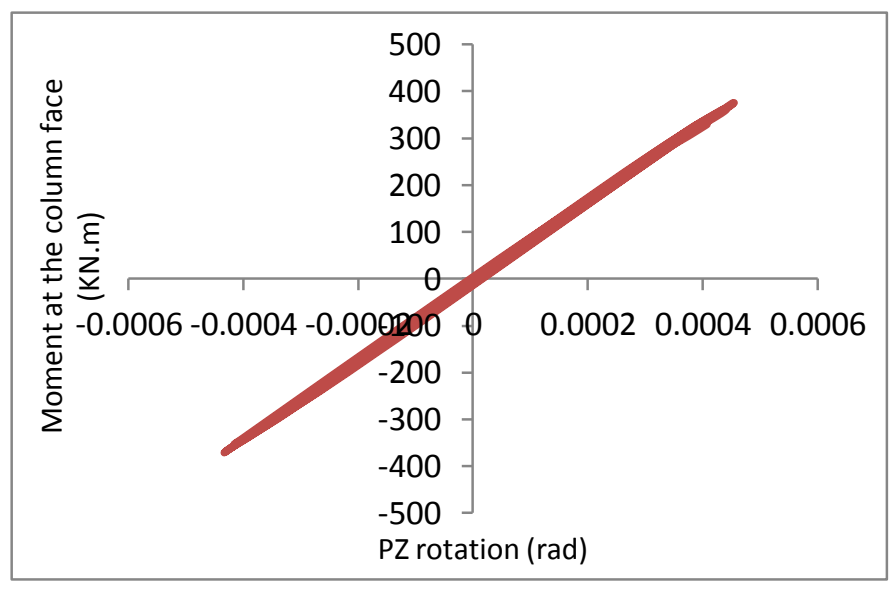

(f) Specimen C240-T

Figure 12. Moment-PZ rotation responses of specimens

\subsection{Comparing Cyclic Behavior of Reinforced and Unreinforced WFP Connections}

In order to compare between the cyclic behavior of unreinforced and reinforced models, we illustrated and compared their moment at the column face vs. story drift relationships. Comparison results, presented in Figure 13, indicated that the use of vertical rib plate on the top and bottom flange plates, delayed the reduction of the connection 
strength in specimens A200-T and B300-T compared to unreinforced A200 and B300 models. In specimen C240 with no rib plate, due to the increase of the moment of inertia, no strength reduction was observed. Reinforcement of this specimen caused better formation of plastic hinges and a slightly increase of its ductility. In reinforced connections, the area of fourth cycle is larger than those of unreinforced connections which resulted in better behavior of reinforced connections.
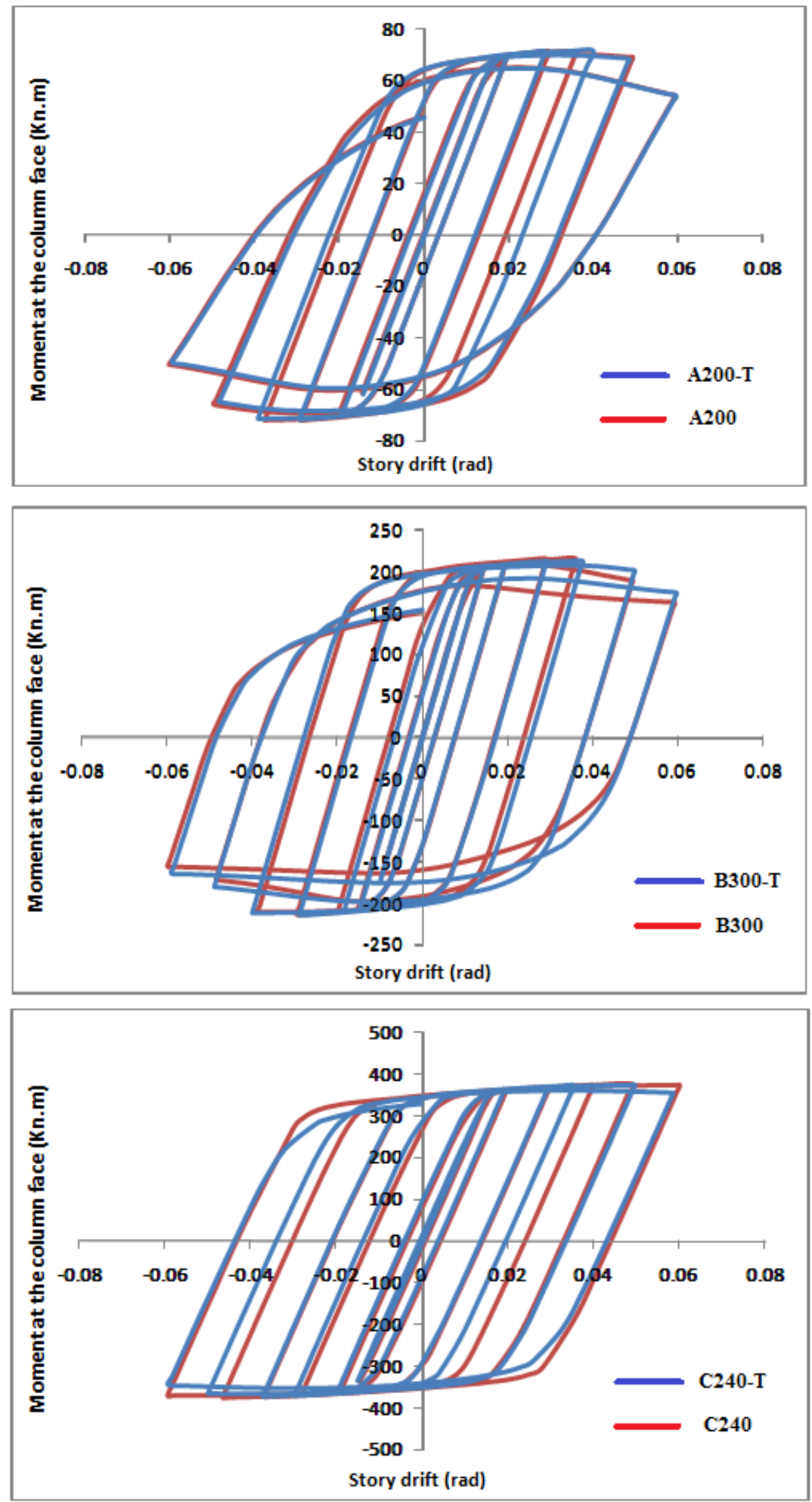

Figure 13. Moment-rotation responses of reinforced and unreinforced specimens

\section{Conclusion}

In this paper, we studied the behavior of WFP connections under cyclic loading. Six models with different beam geometry and flange plate size were studied where three models were reinforced by using a vertical rib plate, and three 
remained unreinforced. It was found out that with the increase of beam height, strength reduction occur sooner due to the local buckling of the beam web and flange after subjecting to cyclic loading. By increasing the moment of inertia in the beam, cyclic behavior of WFP connections became better. By using vertical rib plate for reinforcement, maximum PEEQ index was increased and showed better plastic hinge formation compared to those remained unreinforced. WFP connections with a larger beam height had the potential to brittle fracture in the joint area, and a soft failure in the plastic hinge region. Those WFP connections consist of IPE200 beam sections and a triangular rib plate attached to the top and bottom flange plates satisfied the criteria of AISC seismic provisions to be used in SMFs, but without rib plate, they could not satisfy the acceptance criteria. The top and bottom rib plates could not provide the SMF requirements for the WFP connections with IPE300 beam sections. Moreover, the WFP connections with IPB 240 beam sections, both reinforced and unreinforced, could meet the acceptance criteria for using in SMFs.

In order to compare the cyclic behavior of unreinforced connections with those reinforced by using a vertical rib plate, the hysteric curves of moment at the column face versus story drift were illustrated for specimens. Based on the results, reinforcement with a vertical rib plate delayed the strength reduction in specimen with IPE beam sections and hence, improved their cyclic behavior. In this regard we can say that the WFP connections that could not satisfy the criteria of AISC seismic provisions for SMFs can be reinforced by attaching a vertical triangular rib plate to the top and bottom flange plates in order to delay the web and flange local buckling and hence, to be used in SMFs, although in specimen with IPE300 beam section, the reinforcement with a single rib plate failed to prepare the special moment requirements. Among studied connections, those models with IPB beam sections had the best behavior compared to those with IPE beam sections. They had the ability to reach yield stress and complete plasticity of the beam members before the occurrence of local buckling; i.e. they showed better ductility, while connections with IPE beam sections had different cyclic behavior where those with larger beam height revealed better behavior.

In this study, an exterior joint model of a beam to column connection in a steel frame structure was used. More study is recommended using interior joint model of beam-column connections. Different shapes of flange plates can be employed for further FE analysis of the behavior of WFP connections. In addition, a simple seat angle can be used instead of a triangular rib plate for investigating the cyclic behavior of these connections.

\section{References}

[1] Hedayat, M.A., Jazebi, E., AsadAbadi, S., and Iranpour, A. "Flexural strength prediction of welded flange plate connections based on slenderness ratios of beam elements using ANN." Advances in Civil Engineering (2017). [In Press] https://www.hindawi.com/journals/ace/aip/8059190/

[2] Hernandez, A.A. "Plastic hinge location effects on the design of welded flange plate connections." MS thesis, Department of Civil Engineering, Southern Illinois University Carbondale, USA (2016). http://opensiuc.lib.siu.edu/theses/1863/

[3] FEMA 350. "Recommended seismic criteria for new steel moment frame buildings." Federal Emergency Management Agency, Washington, D.C. (2000). https://www.fema.gov/media-library-data/20130726-1454-20490-9895/fema-350.pdf

[4]. Deylami, A., and Toloukian, A. R. "Effect of Geometry of Vertical Rib Plate on Cyclic Behavior of Steel Beam to Built-up Box Column Moment Connection.” Procedia Engineering 14 (2011): 3010-3018. https://doi.org/10.1016/j.proeng.2011.07.379

[5] Maranian, P., Kern, R., Lyons, R., and Brandow, G.E. "Interim Review on Welded Flange Plate (WFP) Steel Moment Frame Connections." Third Forensic Engineering Congress, San Diego, California, US. (October 19-21, 2003). https://doi.org/10.1061/40692(241)15

[6] Deylami, A., Tehranizadeh, M., and Gholami, M. "The Effect of Beam Depth on the Seismic Behavior of Flange Plate Connections Between Steel Beam and Box." Proceedings of the 15th World Conference on Earthquake Engineering, Lisbon, Portugal (2012). http://www.iitk.ac.in/nicee/wcee/article/WCEE2012_3329.pdf

[7] Lee, K.M., Chen, L.Y., and Li, R. "Cyclic Testing of Welded Free Flange Type and Welded Flange Plate Type Weak-Axis Steel Moment Connections.” Applied Mechanics and Materials, 204-208 (2012): 2922-2931. 10.4028/www.scientific.net/AMM.204-208.2922

[8] Saneei Niaa, K., Mazroi, A., and Ghassemieh, M. "Cyclic performance of flange-plate connection to box column with finger shaped plate.” Journal of Constructional Steel Research 101 (October 2014): 207-223. https://doi.org/10.1016/j.jcsr.2014.05.016

[9] Hedayat, A.A, Saffari, H., and Jazebi, E. "Effect of Beam Flange and Web Slenderness on the Performance of Welded Flange Plate Connections.” Iranian Journal of Structural Engineering 2(2015): 120-130. http://ijse-acecr.com/index.php/ijse/article/view/51

[10] Hedayat, A.A, Saffari, H., and Jazebi, E. "Investigation of the effective parameters on the strength and ductility of the welded flange plate connections." Asian Journal of Civil Engineering 17(2016): 15-42. http://ajce.bhrc.ac.ir/Journal-VolumesIssues/agentType/View/PropertyID/6451

[11] Kosarieh, A.H., and Danesh, F. "Effects of panel zone yielding on seismic behavior of welded-flange-plate connections." Bulletin of Earthquake Engineering 14(2016): 2805-2825. https://doi.org/10.1007/s10518-016-9915-6 
[12] Kosarieh,A.H., Danesh,F., and Shiri, R. "Column Axial Load Effects on Performance of Panel Zone in Welded-Flange-Plate Connections." Advances in Structural Engineering 18 (2015): 775-789. https://doi.org/10.1260/1369-4332.18.6.775

[13] Gholami, M., Tehranizadeh, M. , and Deylami, A. "Evaluation of welded flange plate connections between steel beams and box columns." Advanced Steel Construction 9(2013): 59-76. https://doi.org/10.18057/ijasc.2013.9.1.5

[14] Farooghi Mehr, M.R., and Ghobadi, M.S. "Seismic performance of retrofitted WFP connections joined to box column using ribs.” Journal of Constructional Steel Research 137 (October 2017): 297-310. https://doi.org/10.1016/j.jcsr.2017.06.033

[15] Department of National Building Codes. "Tenth topic: Design and Implementation of Steel Buildings, 4th edition" Research Center for Roads, Housing and Urban Development, Tehran (2013).

[16] American Institute of Steel Construction. "Seismic provision for structural steel building." American Institute of Steel Construction, Chicago, Illinois (2005). https://www.aisc.org/globalassets/aisc/publications/standards/seismic-provisions-forstructural-steel-buildings-ansi-aisc-341-16.pdf

[17] Kaufmann, E. J. "Dynamic tension tests of simulated moment resisting frame weld joints." Structural Steel Education Council, Moraga, CA. (1997). http://www.steeltips.org/steeltips/tip_details.php?id=44

[18] Krawinkler, H. "Guidelines for Cyclic Seismic Testing of Components of Steel Structures for Buildings," Report No. ATC-24, Applied Technology Council, Redwood City, CA. (1992). https://www.atcouncil.org/files/ATC-24TOC.pdf. 